\title{
Optimization Study on Logistics Distribution of Large Chain Supermarkets
}

\author{
Hu Qiong \\ Financial Department \\ Shengyang Aerospace University \\ Shengyang China \\ 425988825@qq.com
}

\begin{abstract}
With the development of large chain supermarket booming rapidly, unified delivery distribution intensified the sustainability and operability, which has close correlation with logistics distribution, logistics distribution. The efficiency and operation condition directly affects operation and development of large supermarket chains. In recent years, with rise and development of electronic commerce, the logistics industry is becoming more and more focused for enterprises. For large supermarket chains, with the continuous development of economy and market scale, the enterprise is becoming more and more convergence in the diversification of product quality requirements. Improvement of the level of customer service accurately and timely meet customer diversification requirements, and become the key for enterprises to win. Logistics distribution plays an important role. Thus improving the efficiency of logistics distribution and optimization of logistics distribution mode will be for a long time as our research subject.
\end{abstract}

Keywords : Large chain supermarket, Logistics distribution, Optimization study

\section{INTRODUCTION}

Large chain supermarket chains as a emerging sales model in the industry has not only brought about a new round of innovation and development for the world economy, but also fundamentally changed the traditional marketing mode and promoted development of retail business. Closely related to large chain supermarkets is the logistics distribution system. Many factors including whether logistics distribution system is perfect or not and what is the efficiency directly affect the future market competitiveness and the degree of development.

Nowadays many chain supermarkets are growing, but the logistics distribution closely related to the them develop slowly, which leads to constant profit decrease. Therefore, in view of the logistics distribution system for large chain supermarkets, series optimization research makes the direction of logistics distribution specific, professional and informationized. This also makes the optimization of the logistics distribution system more and more important.

\section{PURPOSE OF STUDY}

With rapid economic development, large chain supermarkets are gradually perfect. At the same time, the rapid development of chain supermarkets would certainly speed up updating of the related logistics and distribution system. The further development of chain supermarkets leads to that logistics and distribution demand a more detailed logistics resource chain and a supply chain, which will leads to change of the whole supermarket operation structure. Detailed analysis and discussion on the logistics system for large supermarkets are made in the article. The first discussed is the current status of development. Also discussed is analysis of many factors including requirement on equipment in the logistics course and styles of management. Secondly, aiming at many problems of the present supermarkets, improvement and optimization in the aspect of logistics distribution are discussed.

\section{OVERVIEW OF LARGE CHAIN SUPERMARKETS AND LOGISTICS DISTRIBUTION}

\section{A. Developing Status of Large Chain Supermarkets}

Nowadays, the development of large chain supermarkets are constantly growing. The supermarkets have more and more markets, resource demand and customer demand. Therefore, the marketing concept, marketing model, marketing strategy and channel of large chain supermarkets are keeping pace with the times by constant innovation.

\section{B. Logistics and Distribution}

\section{1) Concept of Logistics and Distribution}

Logistics is the most active mode of operation at present. Logistics refers to the course to entity flow from the supply area to the receiving area. Distribution is sending the products that customers demand according to the requirement of the customers to each designated spot within the corresponding range. So people are used to combining this two set of words.

2) Development Status of Logistics and Distribution

\section{a)Domestic Situation}

According to statistics, in China logistics expenses account for a large proportion in the total cost of goods, and transportation cost is much larger than that in the developed countries. At the same time, the most in the sourced logistics service from China comes from basic service. The smallest part comes from the financial income from value added service and logistics information. Therefore, at present although the demand on logistics is constantly rising, the other kinds of transactions in 
logistics industry are increasing, and logistics service is still at a very important position.

\section{b)Status of Other Countries}

Since the Middle Ages, the rationalization of logistics and distribution is generally stressed in America. In order to produce scale effect in the circulation field, different countries established many modes including the terminal user mode (origin -- center -- the end user) through a series of information network technology, which becomes the basis of further development of logistics and distribution.

Although the logistics mode is constantly renewed, the management problem is still very prominent. The problem is mainly displayed in the disorder of operating procedures. At the same time, the information technology is not perfect. Many information systems including electronic data exchange are rarely used. These seriously hindered the pace of chain supermarkets, which restricts the development of large chain supermarkets.

\section{Development Pattern of Logistics and Distribution}

The development of logistics and distribution is experiencing a constantly updating course. The course transforms from traditional distribution with a small efficiency and a redundancy mode to the new efficient logistics mode. Its purpose is to improve the logistics efficiency, to reduce transportation costs, to save resources and to make recycling for making the logistics and distribution in the practice and innovation steadier and more durable.

The initial logistics and distribution is that business operators send products to their customers for improving the quality of service, improving higher operation profit. The extending and perfecting of this gradually formed the concept of logistics and distribution.

The third-party logistics and distribution has been generally recognized by people and it has become one of ways to reach the fastest economic development in developed countries. The third-party logistics is developing from a-form service to the overall service and to the whole chain of service, and the service is expanding. The tendency of diversified services reflects the perfect combination of management consulting and logistics operation abilities.

\section{Presence of Problems on Logistics and Distribution for Large Chain Supermarket}

1) Low-Degree Specialization and Incomplete Function

At present, most distribution centers are established on the basis of maintaining the original facilities and equipment. Therefore, a lot of equipment does not have complete functions and even choosing equipment is not prepared. Application for information network is still very low.

2) Backward Business Management and Lacked Professional Personnel

Logistics distribution center of large chain supermarket need high quality, high efficiency, standardized management and high quality talents. But now, many enterprises lack understanding of logistics links. They ignored the construction of logistics system platforms and system standardization construction with internal management confusion and lacked high-quality professionals. Their understanding on logistics and distribution only stays in the storage and distribution and they still did not rise to the deep concept of logistics service, which is a problem for many distribution centers.

\section{3) Low Distribution Efficiency and High Cost}

The logistics equipment of large chain supermarkets is still not standardized. Meanwhile, some logistics and distribution sectors exist as independent entities lacking unified management and planning that between the various modes of transport in logistics are the differences of equipment standards. Invalid operation of logistics distribution increases, logistics and distribution efficiency is small and cost enlarges.

4) Backward Information System of Logistics and Low Degree of Standardization

Bar code technology (the main technology in the logistics system) only makes simple operation in the aspect of POS. On other sorting technology, application of the computer system is lacked and this undoubtedly blocks improvement of the efficiency of logistics and distribution.

\section{STUDY ON OPTIMIZATION OF LOGISTICS AND} DISTRIBUTION FOR LARGE CHAIN SUPERMARKETS

\section{A. Optimization Strategy of Logistics and Distribution} for Large Chain Supermarkets

\section{1) Management and Optimization of Logistics} and Distribution

The improvement of the logistics and distribution system for large chain supermarkets should firstly focus on the operation and management of logistics and distribution. The business management includes the standardization of the whole logistics system, coordination between all parts and improvement of personnel quality.

(1)The standardization of the logistics and distribution system demands a perfect system. The first is to establish a strict purchase system which has a high efficiency and does not affect the replenishment and delivery. The second is that the procedure related to logistics and distribution should ensure a small cost and high utilization rate so as to avoid many problems such as the loss of storage or backlog of goods etc. The third is to command the prices at each local logistics market through controlling the related cost control index.

(2)Basically, the close coordination between all sections is aimed to ensure smooth information exchange and to accurately command the dynamic status of the market in different periods in order to improve the logistics distribution information classification, transfer, feedback, etc in a better way.

(3)Improvement of personnel quality is also the key of management. Improvement and establishment of a logistics and distribution system and strong consciousness of service is essential. What is more, deep understanding of logistics operation and improvement of advanced logistics business consciousness should be stressed so as to strengthen their ability to work.

\section{2) Strengthen Construction of Hardware and}

\section{Software for Logistics and Distribution}

The construction of software and hardware facilities for logistics and distribution include infrastructure construction and informationization construction. 
(1)Strengthening the construction of self-built distribution centers by chain supermarkets can make resources obtain efficient allocation. As a large chain supermarket, strengthening the construction of infrastructure is essential to establish a perfect and efficient logistics and distribution system.

In the aspect of transport, the best is to employ a minimum time resource, financial resource and distance resource to deliver goods to each store. At the same time, the loading rate of transport should be improved.

Distribution processing needs perfect linking for the purpose of improving logistics service quality and reducing the total cost of logistics. The process should be safe and economic. Full use of information technology should be made and the periodic repair of some equipment should be made for improvement of the corresponding security.

Distribution needs to improve the efficiency of distribution, to establish a unified distribution standard. Good equipment and management technology should be possessed to ensure a high level of distribution.

The most important on handling is rationalization and mechanic operation for increasingly enlarging the degree of specialization and mechanization level and reasonable selection of handling equipment. The aim is to ensure smooth operation of the whole logistics and distribution process and saving of time and cost.

(2)Informationization is one of main sections of logistics and distribution. Network logistics in the electronic commerce environment has the following features, the information management has permeated into every section of logistics system so that the whole system has many accessing points and so that better understanding of the demand and supply on commodities can be realized. Information flow occupies the absolute advantage status in the whole system and it is over the time, space and regional range. It involves a wide range. This can not only get the local dynamic status, but also obtain the dynamic information on the goods and logistics in other regional chain supermarket, which displays a high efficiency. The system can be well adjusted, which greatly saves manpower, material resources and financial resources.

3) Optimized Logistics and Distribution through

\section{Cooperation with Third-Party Logistics Companies}

The third-party logistics refers to an enterprise's applying its own and other functions and service, using external resources to realize better services for enterprises, which is convenient and fast and can achieve management of logistics and distribution. They have five distribution types including transport service, warehousing and distribution services.

A large chain supermarket has many transactions that it cannot make its self-established distribution center complete all distribution. The third-party logistics can be fully used. So, not only can it get professional services capabilities and cost advantage, but also reduce the risk for focusing on resources and advantages to develop its core business. Also it can improve its logistics distribution management level by using third-party technologies and accumulate more professional knowledge for making each other constantly promoted and follow the well-returned development rode in a better way. .

\section{4) Construction of Green Logistics Distribution}

Green logistics is to realize the goal of green logistics with advanced science and technology or promotion of a series of research through resource saving and waste reduction.

Green logistics is necessary for sustainable development of modern logistics. The rising of the logistic industry has great potential. Now, depending on the rapid development of information technology and constant improvement of social economic level, the demand for logistics is rising, but to have better and faster development of logistics, we should enter the team of green logistics. In addition, green logistics is the key for enterprises to reduce production cost, to obtain best operating efficiency and to promote the long-term enterprise development at the maximum degree. In the course of commodity input and output, process of production and processing assumes a little of time, but most time is used for logistics including storage, distribution and transportation and even environment would be damaged. Therefore, the reference and promotion of green logistics is establishing basis for cost reduction, resource saving and environmental protection. Meanwhile, green logistics stresses on investment of a small amount of capital, and even more important is the green energy saving, efficient and none-polluting. This brings not only reduction of business costs, but also a good reputation effect.

The goal is realized through establishing related laws and regulations related to logistics. Green logistics and distribution is not only the enterprise's own matter, and it also needs the government to give strong support. Only through control by the government, laws and regulations and especially control of pollution source in logistics, better development and strengthening of green logistics can be realized. Therefore, establishing relevant policies including traffic limitation and pollution source reduction, constant enhancement of the policies and timely revision are very important. This can become part of the pressure for enterprises, and can also provide development opportunities for enterprises so as to promote smooth development of green logistics.

Concept of green logistics management should be promoted. The choice of green transportation can make full use of vehicles and enlarge the loading rate in vehicle transportation. Full use of the interior space improves distribution plumpness, reduces the running back and forth of the vehicle, and reduces consumption. Selection of optimal distribution routes and rational planning of goods transportation ranges should be made for sending goods to more shops in a short time. Logistics enterprises should promote the use of green packaging and distribution for improvement of sustainable reuse and packaging must use a small space. In the aspect of the logistics flow production, the use of resources should be increased to reduce environmental pollution and article waste. Waste generated in the process can be recycled.

\section{CONCLUSION}

Logistics and distribution is a necessary part of the development of large chain supermarkets. Optimization and research is good for the long and stable development of large chain supermarket. Practice proves that the 
existing large chain supermarkets still do not have a perfect logistics and distribution system and they lack standardization and effective operation management system. This article aims to analyze the present logistics situation of large chain supermarkets. On some problems in the aspects of distribution facilities, management and efficiency, the causes of these problems are analyzed and the optimization measures are put forward to optimize the logistics and distribution of large chain supermarkets.

Through the research on logistics and distribution optimization of large chain supermarkets in the article, we can see that logistics and distribution systems are tending to be systematic, internationalized and informationized. In the future, convenient and efficient logistics and distribution make development of large chain supermarket chains more profitable, reliable and diversified.

\section{REFERENCE}

[1] Cheng Honghai, Theory and Practice on Management of Distribution Center, Tsinghua University Press [M], 2011. 01
[2] An Qingquan, Logistics Standardization -- Mark of Modern Logistics Development [J], Statistics and Consultation, 2011, (1): 64,

[3] Xu Shaobo and Yin Bo, Study on Third-Party Logistics Development [J]China Logistics and Purchase 2011 (5): 76-77

[4] Li Wen, Discussion on Optimization of Logistics and Distribution for Large Chain Supermarkets [J], Intelligence. 2011 (06): 330

[5] Cui Yunling, Development trend of Logistics and Distribution for Chain Supermarkets [J], Guide to Business, 2011 (09):143

[6] Xu Yunjuan, Analysis of Logistics and Distribution for Chain Supermarkets in China [J], Securities and Futures of China, 2011(06):110.

[7] Li Zhenyu, Better Application and Research on Enterprises and Logistics Management [D] Dalian Maritime University, 2012

[8]International Logistics :The Management of International Trade operations[M] Pierre David ,Richard Stewart.2011.4

[9]Andrew C. Lyons, Chiung_lin Liu-An analysis of third-party logistics performance and service provision[J] Transportation Research Part E: Logistics and transportation Review,2011,(47), vol 21. 